\title{
What helps or hinders the Emotional Intelligence practice? A study of Vietnamese hotel workers
}

Authors:

Dr. Quynh Nguyen - University of Essex

Professor Adele Ladkin - Bournemouth University

Dr. Hanaa Osman- Bournemouth University

\section{Abstract}

Purpose - Drawing from emotional labour (EL) and emotion regulation (ER) theories, the paper identifies what helps and what hinders the Emotional Intelligence (EI) practice of Vietnamese hotel workers. Researching EI qualitatively from a novel context highlights the influence of culture on EI.

Methodology - The Critical Incident Technique (CIT) was adopted as the qualitative methodological approach using a self-administered form and semi-structured interviews to collect empirical data from a sample of 34 Vietnamese hotel workers in 19 different hotels.

Findings - The findings show that following Joseph and Newman's (2010) cascading model of EI would help hotel workers in their practice. The research also found different factors hindering the EI practice from the individual and organisational levels. Vietnamese culture was believed to guide deep-acting and meditation. Language barrier and manager support emerged as significant factors that could help or hinder their EI practice.

Implications - The research proposes a conceptual framework addressing the factors that could help or hinder the EI practice and provides implications for HR practices and management. Caution could be taken when applying the research implications due to the small sample as a nature of qualitative research.

Originality - This is the first attempt to appraise the EI practice adopting the CIT as a qualitative methodological approach in an under-research context, and add evidence to the theoretical links between EI, EL, and ER.

Key words - Emotional Intelligence, Emotional labour, Emotion regulation, Critical Incident Technique, culture 


\section{Introduction}

Managing emotions in the workplace has emerged as a powerful and challenging issue for most organisations given its impacts on employee morale and productivity (Kalwani and Mahesh 2020). Two areas of research dominating inquiry into the role of emotions in organisations are emotional labour (EL) and emotional intelligence (EI). EL represents one of the most studied aspects of emotions and work in the hospitality and tourism industry (Lee and Madera 2019a), defined as a form of emotional regulation in which workers are expected to display certain emotions as part of their work role (Grandey and Gabriel 2015). EL highlights employees' effortful emotion management through two strategies - surface and deep acting (Grandey and Melloy 2017). Moreo et al. (2019) also confirmed a significant impact of service providers' EL on customer satisfaction and loyalty.

Whereas EL focuses on the display of emotions in the workplace, EI was defined as the ability to reason with emotion-related information and use emotions to enhance thought (Mayer et al. 2016). Hospitality researchers (Kim et al. 2012; Lee and Ok 2012) found that EI is one of the key drivers determining EL acting strategies and individuals with higher levels of EI are able to manage emotions and regulate behaviours in response to the situation of emotional demands. EI has gained a strong position in organisations because managers are more interested in changing behaviours for better work results (Lopes 2016). Hotel employees' EI was found to affect their retention and performance (Prentice et al. 2020) and moderate the relationship between workplace incivility and job satisfaction (Chen and Wang 2019) whereas managers' EI was reported to significantly impact employees' job satisfaction leading to better service performance (Han et al. 2017) and create a competitive advantage for the organisation (Stoyanova-Bozhkova et al. 2020).

Nevertheless, research on EI is predominantly quantitative with the aim of measuring the relationship between EI and other work-related factors such as job satisfaction (Knežević et al. 2021), leadership (Genc and Kozak 2020) or training (Min et al. 2020). The current literature on EI might have turned the observational data into statistics which are sold as attempts to measure EI in the organisational environment (Lincoln 2009). There exists a lack of studies to investigate the EI process in service failures and recovery (Koc 2019). Keefer et al. (2018) suggested future research on EI may benefit from taking into account the social context in which EI operates. 
In a similar vein, Hosie et al. (2016) stress that EI research needs to address the well-founded practice of self-reflection, contemplation and meditation in Eastern cultures. Individuals in a collectivist society tend to suppress their own emotions for the benefit of the collective (Gunkel et al. 2014). Asian values were found to determine one's EI through such coping mechanisms as family support, meditation/exercise and substance use as well as optimism (Lei and Pellitteri 2017). Through its long history, Vietnam is amongst the few countries sharing the cultural roots with Southeast, East and South Asia as well as Chinese ideologies and religious beliefs (Pham 2015; Nguyen and Truong 2016). The current study aims to investigate the EI practice of Vietnamese hotel workers using a qualitative approach. In pursuit of this, the current research adopted Grandey's (2000) conceptual framework drawn from theories of EI, EL and ER to explore what helps and what hinders the EI practice of Vietnamese hotel workers.

The paper is organised in the following way. The first part reviews theories and current literature on EI, ER, and EL and discusses the relationship between these concepts reflected in Grandey's (2000) conceptual framework. The paper then presents how the Critical Incident Technique (CIT) and semi-structure interviews were conducted. The third section reports findings and discussion from the CIT and semi-structured interviews. In the last section, theoretical implications are discussed alongside with practical implications, limitations and future research.

\section{Review of theories and literature \\ 2.1 Emotional Intelligence (EI)}

There are three main approaches to EI which vary in terms of conceptualisation and measurement. The first group of scholars view EI as a cognitive ability and are mainly based on the initial conceptualisation proposed by Salovey and Mayer (1990). The second group posits that EI is determined by individual's personality named as trait-based EI (Petrides 2010). In the third approach, EI is believed to be a combination of both cognitive ability and personality, known as mixed EI (Goleman 1995; Bar-On 2006). These approaches were followed by the several definitions and measures (McCleskey 2014).

The mixed EI has received criticism for conceptualising EI as an umbrella term for a wide range of personal competencies and abilities and overlapping with Big Five personality traits, which undermines the credibility of the approach (Sternberg 2001; Joseph and Newman 2010). The ability EI is considered more scientifically rigorous than the mixed EI (Daus and 
Ashkanasy 2005; Matthews et al. 2006) and has been widely recognised in academic research (Prentice et al. 2020). Thus, the current research has adopted Mayer and Salovey's (1997) cognitive ability EI comprising of four components - emotion perception, emotion facilitation, emotion understanding, and emotion regulation. Drawing from Mayer and Salovey's (1997) ability-based EI model, Joseph and Newman (2010) excluded the emotion facilitation due to its conceptual redundancy against emotion regulation and the lack of empirical support. However, these two models agree on the hierarchy of the EI model ranging from basic to more psychologically complicated components. The conceptualisation of each component was used to identify and label the specific abilities performed by Vietnamese hotel workers in their interactions with customers.

\section{$2.2 \mathrm{El}$ and Emotion regulation (ER)}

Gross and Barrett (2011) define ER as the processes that could determine the experience or expression of the emotion when it is triggered. There exists a strong relationship between EI and ER through EI conceptualisation and empirical research (Wranik et al. 2007; Lawrence et al. 2011). ER is included as the fourth dimension of the ability EI model - "the conscious regulation of emotions" (Mayer and Salovey 1997, p.14). In a similar vein, Joseph and Newman (2010, p.58) suggest their cascading model of EI is a "conscious emotion regulation process" in which the relationship between the ability to perceive emotion and the ability to regulate emotion is mediated by the ability to understand emotion. Haver et al. (2014) found that hotel general managers cannot perform ER if they do not possess EI whereas Cho et al. (2016) reported that front-line employees' ER could moderate their emotions in stressful situations.

\section{$2.3 \mathrm{El}$ and Emotional labour (EL)}

Hochschild (1983) defined EL with two strategies of emotional management; surface-acting refers to the regulation of one's emotional expressions, and deep-acting relates to the modification of one's feelings to express the required emotion. Hospitality managers and frontline employees were found to use surface and deep acting similarly due to the display rules and social expectations (Lee and Madera 2019b). Grandey (2000) draws the definition of EL from Gross's (1998) theory of ER, considered as the most influential approach for successive theoretical and empirical research on EL (Diefendorff et al. 2008). Grandey (2000) incorporated the antecedents and consequences of EL in a conceptual framework (See Figure 1) to emphasise the different situations faced by employees in the workplace, which is found 
to be a caveat in existing EL and ER studies. Thus, the conceptual framework is relevant for the current study to understand the EI practice in hospitality service encounters.

Apart from the theoretical relationship, there is a growing number of empirical studies evaluating the relationship between EI and EL. Joseph and Newman (2010) reveal that EI positively predicts performance for high EL jobs and negatively predicts performance for low EL ones. Furthermore, it is emphasised that work roles involving frequent customer contact are likely to require higher levels of some certain EI competencies (Newman and Smith 2014).

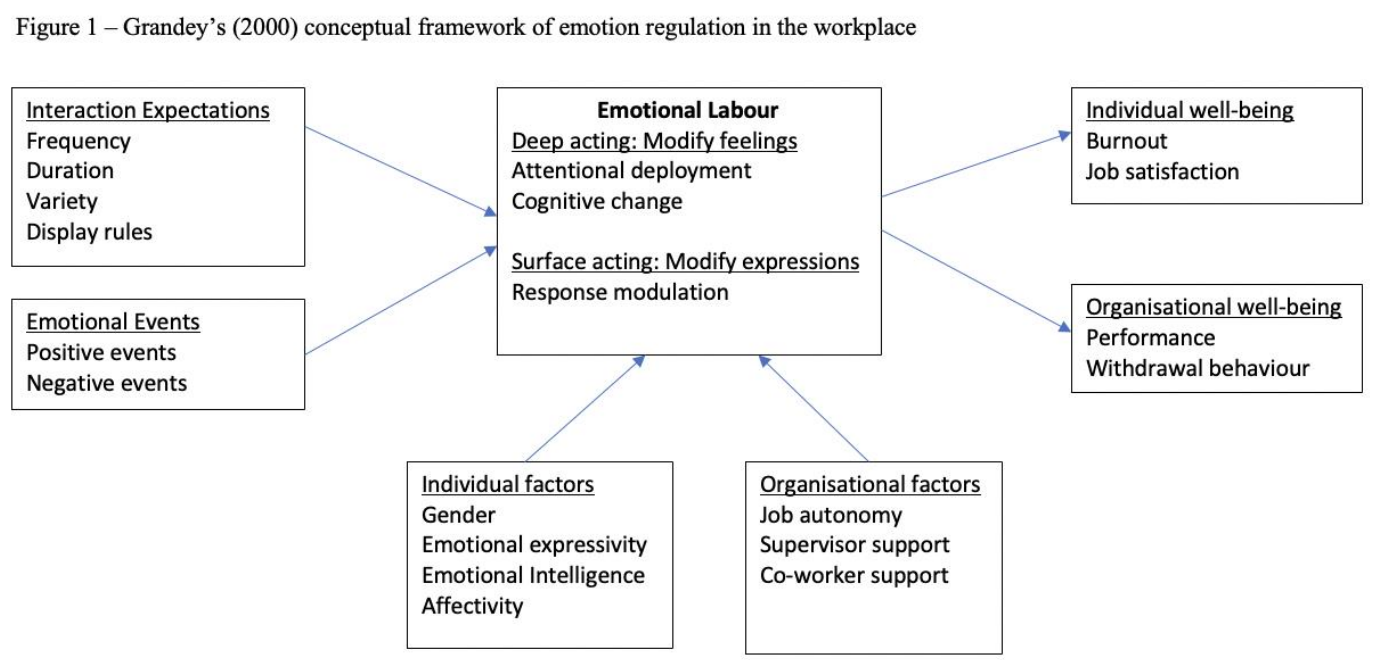

\subsection{The influence of culture on El}

Culture is defined as "the collective programming of the mind which distinguishes the members of one human group from another" (Hofstede 1984, p.21). Members from different cultures may have different perceptions, interpretations, and evaluations of the same things, leading to different acts upon them (Adler 1991). There is a substantial body of research highlighting the influence of culture on emotional expression and regulation and the differences between the East and the West (Schimmack 1996; Elfenbein and Ambady 2002; Davis et al. 2012). Miao et al.'s (2021) meta-analysis found that EI positively influences hospitality workers' job performance across cultures and this effect is stronger in feminine cultures where individuals tend to be modest, caring and sympathetic compared to masculine cultures. 
Markus and Kitayama (1991) propose that people from different cultures have radically different interpretation of the self, others and the interdependence of the self with others leading to individual experience of cognition, emotion and motivation. Those who are capable of understanding and managing their own emotions are not necessarily skilled at comprehending and adapting to feelings of individuals from other cultures in cross-cultural interactions (Moon 2010). That is, EI might just simply be a function of national culture which makes individuals express and act on emotions differently (Prati et al. 2003; Antonakis 2004).

\section{Methodology}

\subsection{Critical Incident Technique (CIT)}

The traditional CIT was introduced by Flanagan (1954) as a tool for observing and categorising human behaviours to solve practical problems. Although CIT data can be analysed quantitatively and qualitatively and have been used in both ways in service research (Gremler 2004), Butterfield et al. (2005; 2009) found CIT studies tend to be qualitative and explore what might help or hinder some experience or activity. To this end, Viergever (2019) argued that CIT is an inductive, qualitative methodological approach to accurately report participants' views, making data analysis rather descriptive. The application of the CIT methodology also focuses on solving practical problems (Kemppainen 2000). This approach is appropriate for the research questions and thus applied for the current study.

\subsection{Semi-structured interviews}

In addition to self-administered questionnaires, face-to-face interview was considered the most satisfactory method for collecting details about the critical incidents (Kemppainen 2000). Interviews are appropriate for exploratory studies where the researcher is interested in 'what', 'why', and 'how' people say things (Bryman and Bell 2011; Saunders et al. 2012). The questions used for the CIT form and the interviews are as follows.

Describe a situation when you had a favourable interaction with customer(s) at your hotel.

- When did it happen?

- What happened?

- What did you and/or others say or do?

- How did you feel?

- What did you do to manage your emotions and the emotions of others? 
- What made you feel that the incident was particularly favourable?

The same questions were asked about an unfavourable interaction with customers.

\subsection{Sampling}

The study adopted purposive sampling to ensure the research questions are answered and the objectives are met by selecting suitable cases (Saunders et al. 2012). Invitations to take part in the research were sent to the Human Resource (HR) department of several hotels in a tourist city on the South-Central coast of Vietnam emphasising the recruitment criteria: hotel workers having a high degree of face-to-face contact with customers regardless of age, academic background, position or the hotel ranking. In addition, snowball sampling where participants nominate others with knowledge of the research issue was employed because hotel workers are not easy to find or access (Jones et al. 2013). The participants preferred Facebook to emails for communication in the snowball sampling process in Vietnam.

\subsection{Data collection}

The data was collected from 34 participants working in 19 hotels across the city in September and October 2016. Together with the information sheet and informed consent, CIT forms were sent to participants asking them to describe one extremely favourable interaction and one extremely unfavourable interaction with customers in their hotel. After three to five days, they were contacted again to arrange an individual face-to-face interview. The CIT form served as a screening tool; some participants turned down the invitation due to the low degree of interacting with customers in their positions. Some incidents collected from the CIT forms were insufficiently described, which is a downside of utilising the self-administered form to collect in-depth stories since the participants were unable to write a complete or understandable story (Edvardsson and Roos 2001). This limitation is reflected in the low response rate; only 7 out of 34 participants completed the CIT forms before the interviews, the majority used the CIT forms to recall their stories prior to the interviews, allowing for follow-up or probing questions.

As a natural phenomenon of human memory, the participants may either forget parts of the incidents or deliberately forget parts that they do not want to recover (Connerton 2008). CIT was used to ask about extremely favourable or unfavourable incidents; therefore, they tend to be memorable to the participants, reducing chances of inaccuracies. Those who completed the CIT forms before the interviews seemed to better articulate their experiences when answering 
probing questions, making it easier for the researcher to grasp the meaning and process of the incidents. These interviews lasted between 30 and 60 minutes and took place at the participants' workplace or house. All interviews were recorded on an iPhone, transcribed verbatim and stored onto NVivo 12. A total of 37 favourable and 34 unfavourable incidents were collected through the CIT form and semi-structured interview. The research followed the ethical process of the authors' institution, using pseudonyms for the participants and the hotels in interview transcripts to reinforce confidentiality and protection of those involved.

\subsection{Data analysis}

Viergever's (2019) five steps of the CIT has been adopted for the study (see Table I).

Table I - The application of Viergever's (2019) five steps of the CIT

\begin{tabular}{|l|l|}
\hline \multicolumn{1}{|c|}{ Viergever's five steps of the CIT } & \multicolumn{1}{c|}{ How it was applied in the current study } \\
\hline $\begin{array}{l}\text { (1) description of the aim of the activity under } \\
\text { study }\end{array}$ & $\begin{array}{l}\text { Aim: Explore what helps and what hinders the EI practice } \\
\text { of Vietnamese hotel workers }\end{array}$ \\
\hline $\begin{array}{l}\text { (2) specifications of the nature of the critical } \\
\text { incidents to report and participants' } \\
\text { characteristics }\end{array}$ & $\begin{array}{l}\text { Nature of the critical incidents: extremely favourable and } \\
\text { unfavourable interactions with customers in hotels. These } \\
\text { are defined as favourable or unfavourable from the } \\
\text { participants' perspective. } \\
\text { Participants' characteristics: hotel workers having a high } \\
\text { degree of face-to-face interactions with customers. }\end{array}$ \\
\hline $\begin{array}{l}\text { (3) data collection on what participants } \\
\text { perceive to be factors or behaviours that help } \\
\text { or hinder in the activity }\end{array}$ & $\begin{array}{l}\text { Collecting data focused on the process of the interactions } \\
\text { and what made it favourable or unfavourable. }\end{array}$ \\
\hline $\begin{array}{l}\text { (4) data analysis by grouping the critical } \\
\text { incidents into themes and sub-themes that } \\
\text { have practical utility }\end{array}$ & $\begin{array}{l}\text { The critical incidents were grouped into themes } \\
\text { highlighting the common factors or behaviours leading to } \\
\text { favourable or unfavourable interactions. }\end{array}$ \\
\hline $\begin{array}{l}\text { (5) interpretation and report of the results } \\
\text { together with evaluation of limitations and } \\
\text { biases }\end{array}$ & $\begin{array}{l}\text { The results were interpreted in combination with findings } \\
\text { from the interviews. Limitations and biases were also } \\
\text { acknowledged in the section on future research. }\end{array}$ \\
\hline
\end{tabular}

The participants' description of the incidents was saved onto NVivo 12, combining the information from the CIT forms and interviews. These incidents were read, re-read and categorised into themes. There existed some differences in the analysis of favourable and unfavourable incidents. The favourable incidents were compared against the ability EI model to identify the components of EI mentioned by the participants. The process was applied for the unfavourable incidents but showed no link between the themes. Grandey's (2000) conceptual framework was also employed to cross-check the themes. 


\subsection{Participant information}

The sample comprised of 34 hotel employees working in Front Office (FO), Food and Beverage (FB), Housekeeping (HK), and Sales departments in 19 hotels ranging from two to five stars (See Table II). The majority of the participants are male (20 out of 34). More than half (18 out of 34) of the participants are in the age group of 20-29 and there were only three participants aged between 40 and 49, which implies a young group of hotel workers taking part in the research. The sample includes 14 front-line employees and 20 supervisors or managers. 
Table II - Participants' demographics

\begin{tabular}{|l|l|c|c|c|c|l|}
\hline Number & Pseudonym & Age & Gender & $\begin{array}{c}\text { Industry } \\
\text { experience } \\
\text { (years) }\end{array}$ & $\begin{array}{c}\text { Hotel star- } \\
\text { rating }\end{array}$ & Position \\
\hline 1 & Linh & 25 & M & 5 & 3 & FO Supervisor \\
\hline 2 & Man & 30 & M & 4 & 3 & FB staff \\
\hline 3 & Nga & 26 & F & 2 & 3 & HK Supervisor \\
\hline 4 & Thi & 47 & M & 8 & 3 & HGM \\
\hline 5 & Hung & 33 & M & 10 & 5 & Sales officer \\
\hline 6 & Huong & 23 & F & 1 & 3 & FO staff \\
\hline 7 & Huy & 23 & M & 5 & 4 & Sales officer \\
\hline 8 & Khoi & 37 & M & 14 & 5 & Laundry Manager \\
\hline 9 & Van & 37 & F & 1.5 & 5 & Business Centre Officer, FO \\
\hline 10 & Ngoc & 26 & F & 4 & 4 & Sales officer \\
\hline 11 & Vien & 28 & M & 8 & 4 & HGM \\
\hline 12 & Truong & 39 & M & 6 & 3 & HGM \\
\hline 13 & Lan & 30 & F & 9 & 5 & Assistant to FB Manager \\
\hline 14 & Truc & 38 & M & 12 & 5 & FO Manager \\
\hline 15 & Tran & 25 & F & 3 & 4 & Cashier \\
\hline 16 & Hoan & 25 & M & 4 & 4 & FO staff \\
\hline 17 & Thinh & 33 & M & 9 & 5 & FB Manager \\
\hline 18 & Hoa & 25 & F & 4 & 4 & FO Manager \\
\hline 19 & Khoa & 40 & M & 15 & 2 & FO Manager \\
\hline 20 & Ngan & 26 & F & 1.5 & 5 & Trainer \\
\hline 21 & Thuc & 24 & M & 4 & 4 & FO Manager \\
\hline 22 & Huong & 26 & F & 3 & 2 & FO staff \\
\hline 23 & Duyen & 27 & F & 5 & 4 & FO Manager \\
\hline 24 & Lam & 26 & F & 4 & 5 & FO staff \\
\hline 25 & Vy & 24 & F & 1 & 2 & FO staff \\
\hline 26 & Vi & 47 & F & 28 & 4 & HK Manager \\
\hline 27 & Duc & 26 & M & 2 & 5 & FO staff \\
\hline 28 & Vinh & 30 & M & 8 & 5 & HK Supervisor \\
\hline 29 & Thanh & 24 & M & 3 & 5 & FB staff \\
\hline 30 & Dang & 26 & M & 5.5 & 5 & FB Supervisor \\
\hline 31 & Thuy & 32 & F & 12 & 5 & FO Manager \\
\hline 32 & Hau & 31 & M & 10 & 5 & Assistant to FB Manager \\
\hline 33 & Vu & 30 & M & 10 & 5 & FO Manager \\
\hline 34 & Dinh & 32 & M & 15 & 5 & HK Manager \\
\hline
\end{tabular}

\section{Findings and discussion}

\subsection{Favourable incidents}

The analysis of 37 favourable incidents found that the hotel workers expressed some or all of the components of Mayer and Salovey's (1997) EI model with some modifications. The themes 
identified from 37 favourable incidents show that adopting the hierarchy of the ability EI model helps their EI practice, leading to successful service encounters. However, there exist some significant differences in their EI practice. Specifically, all the incidents reflected the hotel workers' ability to perceive customers' emotions (theme 1). 33 out of 37 incidents showed how the hotel workers were able to perceive and understand customers' emotions through more personalised conversations (theme 2). 24 incidents reflected the component of emotion regulation (theme 3) employed in the EI process. There are 7 incidents describing how they performed extra-role behaviour (theme 4). The overall impression was the participants tended to address and regulate their emotions only in challenging situations.

Figure 2 - Themes analysed from the favourable incidents

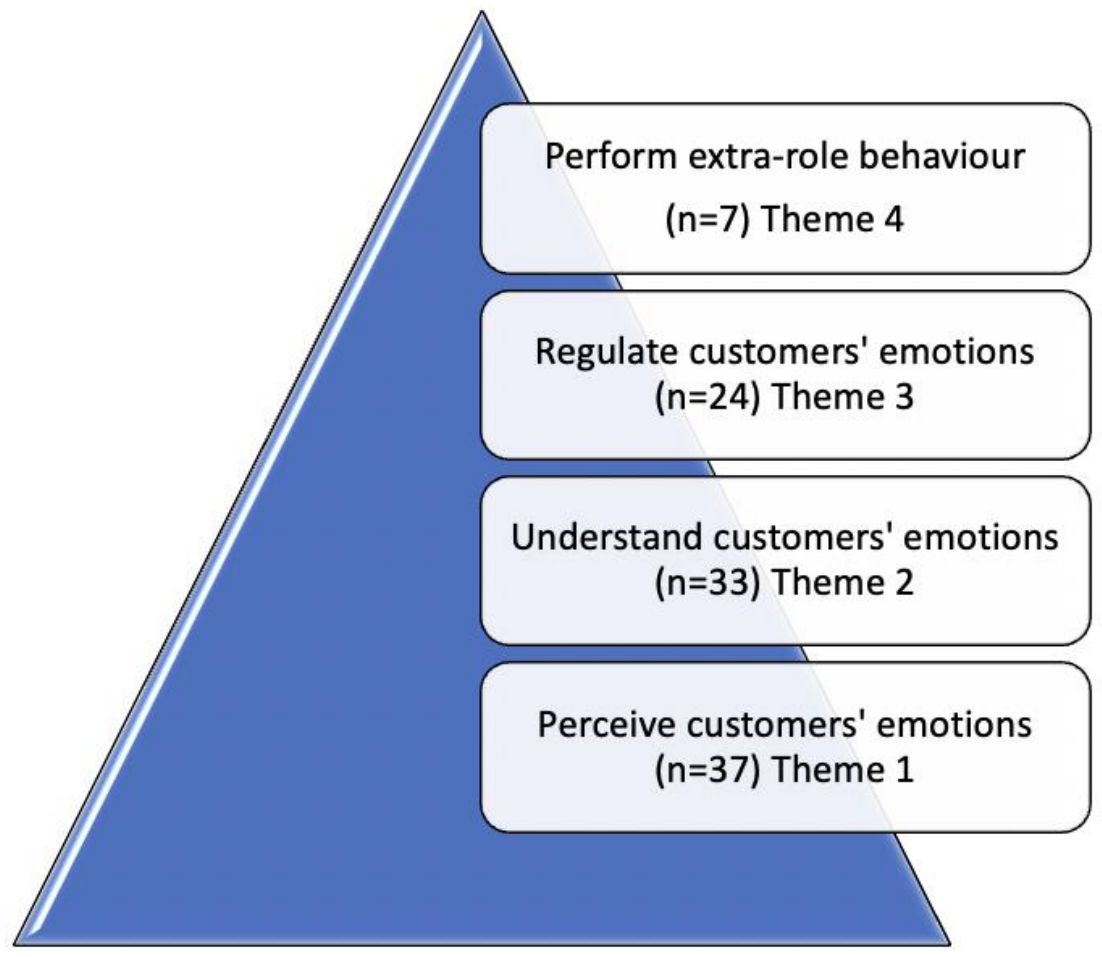

$\mathrm{n}$ : the number of incidents 
All of the incidents reflected the hotel workers' ability to identify customers' emotions. However, emotion played a minor role in these encounters; the emphasis was on their effort to meet customers' needs.

"[The Vietnamese-French couple] enjoy talking to me and other young staff members... It's about taking care of them and offering help. They're quite old, 80 or nearly 90, we prioritise to serve them... We know they like tea and coffee, so we always serve them that, which made them like staying here... FB's interaction with customers is limited to mornings only... We're a city hotel, customers go out for local good, we don't have much time interacting with customers." (Lan)

The incidents in this group ended with positive service encounter without any further interactions. The hotel workers' ability to perceive customers' needs and emotions would not necessarily lead to further interactions to perform higher levels of EI. Instead, they are determined by how often and how long they interact, how they approach their customers, and the emotional expressions they are required to perform. This is in line with Grandey's (2000) proposition that frequency, duration, variety, and display rules are considered as the prerequisites for ER to take place in the work setting.

\section{Theme 2 - Understanding of customers' emotions}

The incidents in this group showed how they developed the understanding of customers' emotions through personalised conversations.

"There's a family of four coming down for breakfast. Luckily, they could speak some English though they're Russian. After the first two days, I knew what they liked... which made them happy and comfortable because they didn't have to speak much... they asked if I wanted to learn Russian and taught me 3 phrases each day like good morning/ afternoon/ evening. They really liked it when I greeted them in Russian the following day." (Ngan)

The incident above is one of those illustrating how the service providers and customers overcame the language barrier and used the language exchange as a tool for enhancing their relationship. The emotion facilitation in Mayer and Salovey's (1997) EI model seemed to be missing from the hotel workers' EI practice. However, the incidents in this group reflect the worker's ability to understand customers' emotions through building their relationships with the customers, which required more frequent and longer interactions. 
The incidents in this group started with some issues in service delivery but they were considered as favourable from the hotel workers' perspective because they managed to resolve the problems and improve customer experience.

"[The Danish students] complained to their teacher that the hotel security guard was brawling with them... their teacher complained to our receptionist. First, I received all the information and apologised to them for what happened, I also promised to look into it and get back to them ASAP. Then I asked the IT staff to check the hotel camera... I showed that clip to the teacher and she apologised to me... The first thing to do is to apologise though I knew it wasn't our fault. My apology is to make them less frustrated at that tense moment and calm them down, then I'd deal with the problem." (Khoa)

Handling customer complaints requires a high degree of understanding and regulating emotions. The incidents in this group emphasise that EI is not only emotion-related abilities but also problem-solving skill. These three components add more empirical evidence to support Joseph and Newman's (2010) cascading model.

\section{Theme 4-Performance of extra-role behaviour}

The incidents in this group reflect the hotel workers' performance of extra-role behaviour as the highest component of their EI practice. Some incidents went smoothly whereas others involved the workers' ability to regulate emotions and solve the problems but the common theme is the extra effort to deliver personalised service.

"When receiving a complaint, I often speak to them and put myself in their shoes to understand their emotions. The customers were frustrated... There's a hair in the bowl of pho... I apologised and showed the empathy with them... I told them "I'll offer you pho another day so that you can taste it better. After the incident, you won't feel good about pho. Let's try another dish." Then I told them about the special offer for buffet... Because they were unhappy, I had to keep the buffet open until midnight and wait for them. They came here at 9pm and invited me to join them." (Hau)

Hau's account is amongst the seven incidents demonstrating how the hotel worker added the personal touch and extra efforts to enhance the customer experience. Interestingly, six out of seven participants who demonstrated all the four stages of the EI practice were in the managerial or supervisory positions. This may imply the distinct difference between hotel managers and non-managers' EI reported by Liu and Cho (2018), job demands only boost the positive impact of EI on work engagement amongst managers. This is in line with Wong and Law's (2002) finding that followers' EI affects job performance and job satisfaction whereas 
leaders' EI affect their satisfaction and extra-role behaviour, highlighting their tendency to go an extra mile for personalised customer experience.

\subsection{Unfavourable incidents}

The findings from 34 unfavourable incidents show a wide range of factors that could hinder the EI practice - individual and organisational factors. Individual factors include the lack of communication (theme 5), lack of experience (theme 6), and inability to regulate emotions (theme 7) whereas organisational factors highlight the hotel revenue outweighing customers' emotions (theme 8), manager support (theme 9), and follow-up procedure (theme 10).

Figure 3 - Themes analysed from the unfavourable incidents

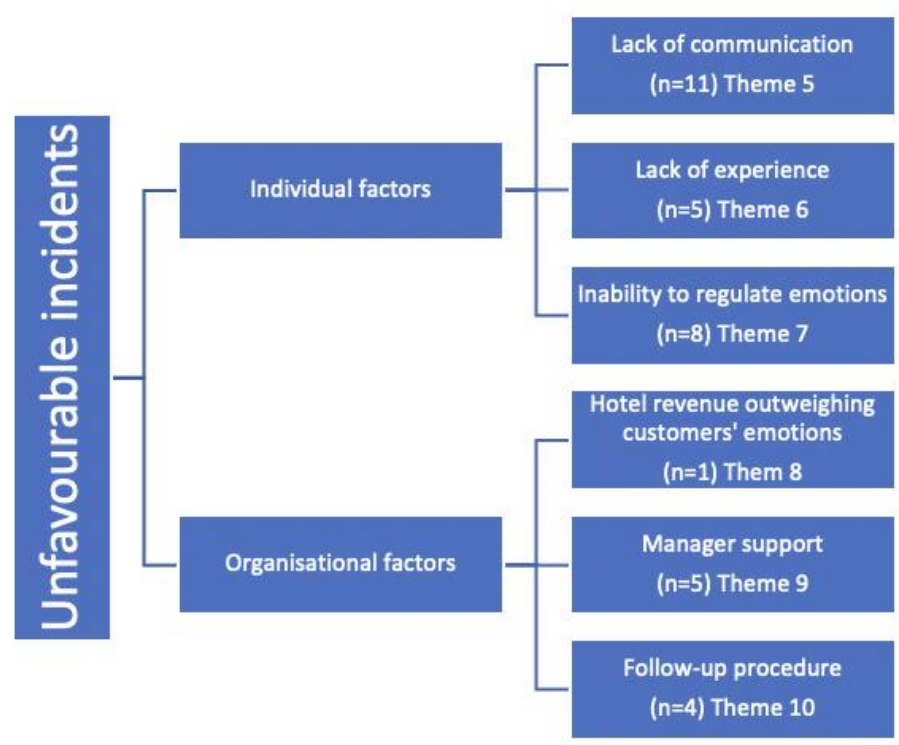

$\mathrm{n}$ : the number of incidents

\section{Theme 5 - Lack of communication}

On the individual level, the hotel workers cited several communication-related reasons including the language barrier, nonverbal communication, a gap in the communication process, or no communication with the workers involved.

"There's something wrong in the kitchen and it would take about 10-15 minutes to fix. I thought the kitchen was ready, so I didn't communicate with the kitchen staff and told the customers that the wait time would be 5-10 mins. Finally, they couldn't have that dish and were annoyed after waiting for it... I admitted my fault and apologised for the 
replaced dish. I wasn't sure if they got it because they're Russian and I spoke to them in English. Their English isn't good." (Man)

Man's account highlighted the gap in the communication between the waiting staff and the kitchen as well as the language barrier between the service provider and the customers. The language barrier prevented the hotel workers from understanding and helping the customers to regulate their negative emotions in service failures. Speaking the same language could sufficiently reduce the chance of misunderstanding and miscommunication (Manzur and Jogaratnam 2006). Domestic customers were found to rate services more positively than the foreign group after the service encounters (Mariani et al. 2019).

\section{Theme 6-Lack of experience}

The incidents in this group illustrate difficulties facing the workers when they started working in hotels.

\footnotetext{
"The customer was drunk, he flirted and asked me out, I refused. Then he asked about 'happy service'... I was a fresh graduate, I didn't know what 'happy service' meant, I thought it means going out. So, I recommended him places to go out at night. "No...", I didn't provide him with the service he asked for, which made him frustrated. He looked so scary... He jumped towards me, took my hand and dragged me out "Let's go to my room." I was so scared, I didn't know what to do, I was almost crying, I just screamed, then the security guard came... The manager comforted me the following day, so I felt better." (Ngoc)
}

These incidents pose the need for training or shadowing to better prepare lay workers for different scenarios they may encounter, enhancing their job performance. It is welldocumented that EI can be improved with age, industry experience, and training (Kim and Agrusa 2011; Fernández-Gámez et al. 2018). In addition, emotional support and empathy from managers were emphasised by the hotel workers who experienced extremely unpleasant interactions with customers such as insult or sexual harassment as in Ngoc's story.

\section{Theme 7 - Inability to regulate emotions}

This group consists of incidents where the customers' complaints were resolved but the emotional tension and psychological distress was still strongly experienced by the customers, the workers or both. Despite their ability to perceive their own and the customers' emotions, the emotion regulation did not generate positive emotions after the interactions.

"They were very frustrated; they said their child was too young [to pay full price]. They were scolding us and wanted to cancel the booking... they even insulted us... I was so angry that my body was shaking... I tried to calm down and showed them the hotel 
regulations and phone numbers of other hotels, they were too stubborn... We could have refunded them but eventually they accepted that though they weren't happy at all. Honestly, I wasn't happy either... I was there with the receptionist, I must be a good example... if I lost my temper, they would do the same." (Truong)

There is a significant number of unfavourable incidents involving the workers' inability to regulate their emotions, emphasising that ER is the most complicated component in Mayer and Salovey's (1997) EI model. The workers were able to perceive and understand the emotions but unable to regulate their emotions or help the customers regulate theirs. There exist some differences; whereas the front-line workers experienced the emotional outburst, the supervisors and managers were able to regulate their own emotions but those of their customers. A potential explanation for this is managers were forced to enhance their EI or those with EI tend to stay in the industry (Scott-Halsell et al. 2011). The proliferation of EI research in the realm of leadership also accounts for this.

\section{Theme 8 - Hotel revenue outweighing customers' emotions}

On the organisational level, the first factor hindering the EI practice is whether the priority is placed on customers' emotions or hotel revenue. It is difficult to accommodate both customer relationship and hotel revenue (Wang 2012). There is only one incident sharing no similarities with others, describing the situation where positive impressions or customers' emotions were not prioritised.

"On the day of check-out, [the travel agency] didn't transfer the money... The relationship with customers built during their stay was destroyed... All the efforts in delivering services, creating happiness and regulating emotions over the last 3 days were 'thrown away'... The customers were frustrated and scolded the receptionists and didn't want to know what the problem was. They're worried about missing the flight home. So, all the happy faces were replaced by angry ones... We tried to be polite and explained the situation... but the customers were really dissatisfied." (Thi)

\section{Theme 9 - Manager support}

This group highlights the role of managers when their employees failed to handle customer complaints. Whereas some incidents show the manager as an authority figure, others consider the manager as a mentor and a source of emotional support. Their timely support impacted not only the services provided but also the hotel workers' emotions as in Vu's account.

"A VIP customer and his friends wanted a BBQ at lam... I persuaded them that it's impossible due to the availability of staff and food... He got angry... He didn't speak to me in English any more but changed to Russian. He stood up and chased me around. His friends were calmer and held him... I spoke to his friend "He's drunk, can you 
explain to him that we can't organize a BBQ right now?" I was very depressed and thought I'd speak to my manager and asked for a holiday; otherwise, I'd have to look for another job. I was so fed up with serving those who can't control their emotions... The following morning, I spoke to my manager, he encouraged me a lot, which made me confident and love my job again." (Vu)

Similar to Grandey's (2000) model, manager support was identified as an important factor facilitating the workers' EI practice and the lack thereof could put the employees under pressure, consistent with previous research that shows the positive impacts of supervisor and manager support on front-line employees (Kang et al. 2015; Choo and Nasurdin 2016; Wang and Xie 2020).

\section{Theme 10 - Follow-up procedure}

The last theme identified from the unfavourable incidents is how hotel workers followed up with their customers after service failures. These incidents illustrate the way the participants regulated their emotions in response to the negative emotions expressed by the customers.

"The customers booked a limousine, but we picked up the wrong customers who had the same surname... They got really angry and rang the hotel. Honestly, I was prepared emotionally, I know what it would be like... I immediately booked a cab to take them to the hotel first. Of course, they weren't happy. The first thing is to apologise, just stand and listen so that they could release their anger. Afterwards, I explained the situation and admitted it's our fault for not confirming both surname and first name... I took them to their room to rest because it's late. I sent an apology letter... When they calmed down, I continued apologising." (Thuy)

The hotel workers were unable to fix the problem that had already disappointed the customers but they showed the service recovery efforts to improve the overall customer experience. The finding has implications for service encounter and service recovery specifically. It also indicates the EI practice does not end in one single service encounter, supporting Ro and Wong's (2012) suggestion for more follow-up after customer complaints. This will also help decrease the memorability of service failures or customers' switching behaviours and negative word-of-mouth (Kim and Jang 2016).

\subsection{The influence of Vietnamese culture on El practice}

An interesting finding emerged from the favourable and unfavourable incidents is the influence of Vietnamese culture on the hotel workers' EI practice. They described hotel work as a "daughter-in-law" job and they are expected to please everyone including managers, supervisors, colleagues and customers. Unlike the English meaning of "in-law"; in Vietnam, 
daughters-in-law are confined by the family norms to serve and submit to their parents-in-law (Werner 2004); this relationship is always critical and unavoidable (Do and Brennan 2015). The saying has described and exaggerated, to some extent, the requirements and pressure facing a hotel employee. This is consistent with Guerrier and Adib's (2000, p.257) comment on hospitality employment which is often perceived as female roles with a lower status and makes hospitality workers "cope with the psychological pressures of smiling and keeping their tempers in response to verbal provocation". This may explain why the participants emphasised the regulation of their emotions in more challenging situations, as the expression of deep acting.

Buddhist meditation was also found to help them regulate emotions.

"Whenever we are in a difficult situation, we need to keep calm and control our breath... to know which thinking is positive... I learn it from the monk Thich Nhat Hanh through YouTube. I also go to Linh Quang Pagoda to meditate with others every week... it becomes a habit and helps me become a calm person." (Duc)

The meditation practice originated from Buddhism, one of the few features inherited from the Chinese legacy (Cleary 1991), encouraging people to minimise the suffering and pain of self and others and abandon a narrow-minded and egocentric mentality (Lyu 2012). This religious practice may strengthen their ability to regulate their own emotions and minimise the influence of customer incivility on employee incivility as noted in Kim and Qu's (2019) study.

Language, as a part of culture, has been neglected in hospitality research, with a few exceptions (Tabari et al. 2016; Mariani et al. 2019). Researching EI from an under-representative context reveals the language barrier as a main issue facing hotel workers in their EI practice.

"A Russian mother and her child, for some reason, always looked so grumpy that the whole team knew it... I really wanted to know what her expectations were but I couldn't due to the language barrier... She showed us the attitude and raised her voice... I tried to solve the problems for her but she talked as if she wanted to release all her stress to the receptionists. I felt helpless." (Thuc)

Though some basic emotional expressions were recognised, little was known about the reasons why the customers were not satisfied. The language barrier was also highlighted in Thanh's two unfavourable incidents. Thanh expressed the empathy, chose proper words and tone of voice when dealing with a Vietnamese customer. Nevertheless, he struggled to understand the Indian customer due to the lack of emotional expressions and verbal communication. That said, the same worker does not necessarily perform well in cross-cultural interactions, reflecting the role of context in the EI practice. This might explain for the increasing interest in the 
relationship between EI and cultural intelligence in the hospitality industry (Darvishmotevali et al. 2018; Lam et al. 2020; Yick et al. 2020).

In addition, several participants described the manager as an authority figure who intervened to moderate the tension between the workers and the customers (as in Thuy and Vu's incidents). Their timely support impacted not only the services provided but also the hotel workers' emotions. Interestingly, the manager was found to either help or hinder the EI practice depending on the degree of their support in challenging situations. The manager support was listed as one of the organisational factors in Grandey's (2000) conceptual framework but the combination of high-power distance and collectivism of Vietnam possibly makes the role of managers more important compared to other countries. Vietnamese subordinates are comfortable with being told what to do and having less autonomy (Nguyen and Truong 2016), suggesting why job autonomy in Grandey's (2000) conceptual framework did not emerge from the findings.

\section{Discussion and Conclusions}

\subsection{Conclusions}

This study investigates how EI is practised in Vietnamese hotels, what helps and hinders it through complete episodes of interactions between hotel workers and customers. Hotel workers were found to follow the hierarchy of EI components including perception of customers' emotions, understanding of customers' emotions, regulation of customers' emotions, and performance of extra-role behaviour, leading to favourable service encounters. The process is similar to Joseph and Newman's (2010) cascading EI model but adds the performance of extrarole behaviour found in supervisors and managers' accounts.

The analysis of unfavourable incidents reflected a range of factors that could hinder the EI practice in terms of individual and organisational factors. On the individual level, the lack of communication, inexperience, and the inability to regulate emotions were reported as the main reasons for unfavourable service encounters. On the organisational level, EI practice could be jeopardised due to the focus on hotel revenue, the lack of managers' support, or follow-up procedures. The unfavourable incidents led to unresolved problems, emotional outburst or exhaustion after the interactions from the customers and service providers involved. 


\subsection{Theoretical implications}

The paper contributes to current understanding of EI in two aspects. First, it adds empirical evidence to the theoretical links between EI, EL, and ER. Exploring how Vietnamese hotel workers practise EI in interactions with customers allows for an understanding of both intrapersonal and interpersonal EI whereas current EI research tends to neglect the latter (Delcourt et al. 2016). The research findings show that EI, ER and EL were closely intertwined in the way hotel workers managed their own emotions and helped customers regulate their negative emotions, particularly in challenging situations. According to the conservation of resources theory, EI serves as a resource enabling service providers to interact with customers (Kim et al. 2012; Lee and Ok 2012). Thus, EI and personality are the most commonly investigated antecedents of EL (Lee and Madera 2019a). In addition, the research findings showed that ER is a more complicated component of the EI process and the inability to regulate emotions led to a sufficient number of unfavourable incidents. Gross' ER strategies tend to be used in interpersonal processes and hospitality leaders cannot perform ER without possessing EI (Haver et al. 2014). Taken together, the current research supports Lindebaum's (2015) proposition that EI feeds into ER instead of EI theories. It is noteworthy that Lindebaum's (2015) is amongst the few qualitative study of EI, suggesting that qualitative approach may direct EI research towards the processes demonstrated in ER theory.

Second, the study suggests that EI practice varies from one worker to another and is determined by individual and organisational factors, highlighting the importance of taking context into consideration when researching EI as a response to the call from previous research (Lincoln 2009; Keefer et al. 2018). Vietnamese culture was found to encourage deep-acting and meditation in emotionally challenging situations. This is in line with Miao et al.'s (2021) metaanalysis, confirming the role of EI in boosting hospitality workers' job performance and this effect is stronger in feminine cultures than masculine cultures. Language was as a key barrier to their EI practice in interactions with foreign customers but language exchange could be used for building relationships with customers. The current research raises the importance of language in EI practice as it provides the basis for the communication between service providers and customers in service encounters (Holmqvist and Grönroos 2012; Holmqvist et al. 2017).

Management support or the lack of it is another significant cultural factor determining hotel workers' EI practice. In a high power-distant and collectivist culture, a manager is considered 
as not only extended-family support but also an authority figure (Hofstede et al. 2010). Therefore, their timely intervention was reported to moderate the negative emotions experienced by their subordinates in the unfavourable incidents. Wu et al. (2020) found that hospitality employees who tend to experience more negative emotions are more likely to value leader humour and support for their psychological needs, boosting harmonious passion for work and enhancing their service performance. Figure 4 presents the proposed conceptual framework of EI components and the factors influencing the EI practice.

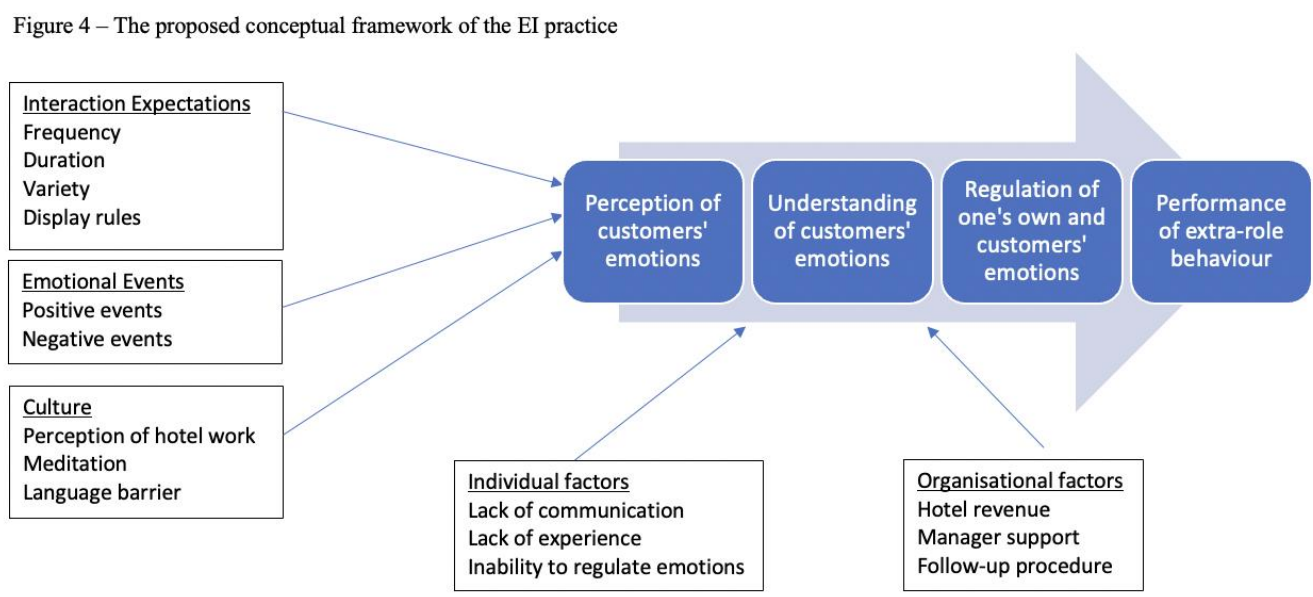

\subsection{Practical implications}

The current study has implications for HR practices and hotel managers. The proposed framework of EI practice can be incorporated into training materials for hotel workers emphasizing the hierarchy of the EI practice from basic to complicated components. Enhancing employees' EI can increase their job satisfaction, which in turn benefit the organization (Jung and Yoon, 2016). Previous research (Lee and Ok 2015; Wu et al. 2017) has acknowledged the importance of incorporating customer orientation, service orientation, EL and EI in the recruitment and selection process of front-line employees, choosing the right people for the job. Given the significant number of individual factors leading to unfavourable incidents, HR departments may focus more on improving employees' emotional management skills. Yu et al. (2020) found that deep acting could reduce emotional exhaustion and workplace deviance amongst generation $\mathrm{Y}$ hotel workers. Vietnamese culture encourages deep-acting and meditation but this may not be the case in other cultural settings, creating space and platforms for hotel workers to share their experience on emotional management would particularly benefit young and inexperienced employees. 
In addition, hotel managers could review their current standard of procedures to highlight touch points for more personalised conversations with customers as well as pain points to decrease the chances of service failure and the negative emotions associated with that. Industry tenure was found as another embodiment of individual aging in the hospitality workplace influencing workers' behavioural responses to shame and improving ER in service failure (Wang et al. 2021). The current study highlights the important role of manager in offering task-related and emotional support in challenging service encounters. Hospitality managers could also reinforce the relevant skills for customer-contact employees and review their recognition and reward programmes. COVID-19 has accelerated the adoption of Artificial Intelligence (AI) technology and robots in hospitality organisations to facilitate social distancing and minimise contagion risk; however, human beings are still preferred to robots in positions requiring social skills and EI (Christou et al. 2020; Ivanov et al. 2020; Romero and Lado 2021). Providing adequate training for employees to perform tasks that cannot be replaced by AI could foster their job security and reduce emotional exhaustion (Kong et al. 2021). In so doing, hotel workers would be motivated to perform extra-role behaviour and genuinely express positive emotions.

\subsection{Limitations and Future Research}

As the first attempt to adopt the CIT to explore the EI practice qualitatively, the study has its limitations in reporting the large amount of data from detailed stories of the incidents. Despite the thematic analysis, each incident has its own line of story. The sample was collected in a city in southern Vietnam, which is neither generalisable nor representative of all Vietnamese hotel workers. Thus, the proposed conceptual framework needs further empirical investigation on a larger scale. The hotel star-rating and policies may warrant additional attention for its impact on the hotel workers' EI practice.

The theoretical relationships between EI, EL and ER present obstacles in researching EI qualitatively. The process underlying ability EI is better defined through the construct of ER (Lindebaum 2015), future researchers of EI should refer to ER theory for a better understanding of EI conceptualisation. The CIT provides in-depth insights into this line of research, future research could include the customers and colleagues' sides of the story to gain a comprehensive view of the critical incidents. 


\section{Acknowledgement}

The work contained in this paper includes key elements of the doctoral thesis of the first author, which is available for reference at http://eprints.bournemouth.ac.uk/32580/

\section{References}

Adler, N. J., 1991. International dimensions of organizational behavior. 2nd edition. Boston, Mass: PWS-KENT Pub. Co.

Antonakis, J., 2004. On why Emotional Intelligence will not predict leadership effectiveness beyond IQ or the Big Five: An extension and rejoinder. Organizational Analysis, 12 (2), 171-182.

Bar-On, R., 2006. The Bar-On model of emotional-social intelligence (ESI). Psicothema, 18 (Suppl), 13-25.

Bryman, A. and Bell, E., 2011. Business research methods. 3rd edition. Oxford: Oxford University Press.

Butterfield, L. D., Borgen, W. A., Amundson, N. E. and Maglio, A.-S. T., 2005. Fifty years of the critical incident technique: 1954-2004 and beyond. Qualitative Research, 5 (4), 475-497.

Butterfield, L. D., Borgen, W. A., Maglio, A.-S. T. and Amundson, N. E., 2009. Using the enhanced Critical Incident Technique in counselling psychology research. Canadian Journal of Counselling, 43 (4), 265-282.

Chen, H.-T. and Wang, C.-H., 2019. Incivility, satisfaction and turnover intention of tourist hotel chefs: Moderating effects of emotional intelligence. International Journal of Contemporary Hospitality Management, 31 (5), 2034-2053.

Cho, M., Bonn, M. A., Han, S. J. and Lee, K. H., 2016. Workplace incivility and its effect upon restaurant frontline service employee emotions and service performance. International Journal of Contemporary Hospitality Management, 28 (12), 2888-2912.

Choo, L. S. and Nasurdin, A. M., 2016. Supervisor support and work engagement of hotel employees in Malaysia : Is it different for men and women? Gender in Management: An International Journal, 31 (1), 2-18.

Christou, P., Simillidou, A. and Stylianou, M. C., 2020. Tourists' perceptions regarding the use of anthropomorphic robots in tourism and hospitality. International Journal of Contemporary Hospitality Management, 32 (11), 3665-3683.

Cleary, J. C., 1991. Buddhism and popular religion in medieval Vietnam. Journal of the American Academy of Religion, 59 (1), 93-118.

Connerton, P., 2008. Seven types of forgetting. Memory Studies, 1 (1), 59-71.

Darvishmotevali, M., Altinay, L. and De Vita, G., 2018. Emotional intelligence and creative performance: Looking through the lens of environmental uncertainty and cultural intelligence. International Journal of Hospitality Management, 73, 44-54.

Daus, C., S. and Ashkanasy, N. M., 2005. The case for the ability-based model of Emotional Intelligence in organizational behavior. Journal of Organizational Behavior, 26 (4), 453-466.

Davis, E., Greenberger, E., Charles, S., Chen, C., Zhao, L. and Dong, Q., 2012. Emotion experience and regulation in China and the United States: How do culture and gender shape emotion responding? International Journal of Psychology, 47 (3), 230-239. 
Delcourt, C., Gremler, D. D., van Riel, A. C. R. and van Birgelen, M. J. H., 2016. Employee Emotional Competence: Construct conceptualization and validation of a customerbased measure. Journal of Service Research, 19 (1), 72-87.

Diefendorff, J. M., Richard, E. M. and Yang, J., 2008. Linking emotion regulation strategies to affective events and negative emotions at work. Journal of Vocational behavior, 73 (3), 498-508.

Do, V. H. T. and Brennan, M., 2015. Complexities of Vietnamese femininities: A resource for rethinking women's university leadership practices. Gender and Education, 27 (3), 273-287.

Edvardsson, B. and Roos, I., 2001. Critical Incident Techniques - Towards a framework for analysing the criticality of critical incidents. nternational Journal of Service Industry Management, 12 (3-4), 251-268.

Elfenbein, H. A. and Ambady, N., 2002. On the universality and cultural specificity of emotion recognition: a meta-analysis. Psychological Bulletin, 128 (2), 203-235.

Fernández-Gámez, M. Á., Rosales-Pérez, A., Molina-Gómez, J. and Mora-Lucena, L., 2018. The effects of outdoor training on the development of emotional intelligence among undergraduate tourism students. Journal of Hospitality, Leisure, Sport \& Tourism Education, 23, 39-49.

Flanagan, J. C., 1954. The critical incident technique. Psychological Bulletin, 51 (4), $327-$ 358.

Genc, V. and Kozak, M. A., 2020. Emotional and social competence in the aestheticization of labor in the restaurant industry. International Journal of Contemporary Hospitality Management, 32 (3), 1201-1225.

Goleman, D., 1995. Emotional Intelligence: Why it can matter more than IQ. London: Scientific America, Inc.

Grandey, A. A., 2000. Emotion regulation in the workplace: a new way to conceptualize emotional labor. Journal Of Occupational Health Psychology, 5 (1), 95-110.

Grandey, A. A. and Gabriel, A. S., 2015. Emotional labor at a crossroads: Where do we go from here? Annual Review of Organisational Psychology and Organisational Behaviour, 2, 323-349.

Grandey, A. A. and Melloy, R. C., 2017. The state of the heart: Emotional labor as emotion regulation reviewed and revised. Journal of occupational health psychology, 22 (3), 407-422.

Gremler, D. D., 2004. The Critical Incident Technique in Service Research. Journal of Service Research, 7 (1), 65-89.

Gross, J. J., 1998. The emerging field of emotion regulation: An integrative review. Review of General Psychology, 2 (3), 271-299.

Gross, J. J. and Barrett, L. F., 2011. Emotion generation and emotion regulation: one or two depends on your point of view. Emotion Review, 3 (1), 8-16.

Guerrier, Y. and Adib, A., 2000. Working in the hospitality industry. In: Lashley, C. and Morrison, A., eds. In search of hospitality: Theoretical perspectives and debates. Oxford: Butterworth-Heinemann, 255-275.

Gunkel, M., Schlägel, C. and Engle, R. L., 2014. Culture's influence on Emotional Intelligence: An empirical study of nine countries. Journal of International Management, 20, 256-274.

Han, S. J., Kim, W. G. and Kang, S., 2017. Effect of restaurant manager emotional intelligence and support on front-of-house employees' job satisfaction. International Journal of Contemporary Hospitality Management, 29 (11), 2807-2825. 
Haver, A., Akerjordet, K. and Furunes, T., 2014. Wise emotion regulation and the power of resilience in experienced hospitality leaders. Scandinavian Journal of Hospitality \& Tourism, 14 (2), 152-169.

Hochschild, A. R., 1983. The managed heart: commercialization of human feeling. Berkeley: University of California Press.

Hofstede, G., 1984. Culture's consequences: international differences in work-related values. Beverly Hills, London: Sage.

Hofstede, G. H., Hofstede, G. J. and Minkov, M., 2010. Cultures and organizations: software of the mind, intercultural cooperation and its importance for survival. 3rd edition. New York: McGraw-Hill.

Holmqvist, J. and Grönroos, C., 2012. How does language matter for services? Challenges and propositions for service research. Journal of Service Research, 15 (4), 430-442.

Holmqvist, J., Van Vaerenbergh, Y. and Grönroos, C., 2017. Language use in services: Recent advances and directions for future research. Journal of Business Research, 72, 114-118.

Hosie, P., Sharma, A., Herkenhoff, L., Heydenfeldt, J. A. and Kingshott, R. P. J., 2016. Emerging HRM perspectives on emotional intelligence, mindfulness and neurobiological science on organisational effectiveness. In: Nankervis, A., Rowley, C. and Salleh, N. M., eds. Asia Pacific Human Resource Management and Organisational Effectiveness: Impacts on Practice. London: Chandos Publishing, 3963.

Ivanov, S., Seyitoğlu, F. and Markova, M., 2020. Hotel managers' perceptions towards the use of robots: a mixed-methods approach. Information Technology \& Tourism, 22 (4), 505.

Jones, I., Brown, L. and Holloway, I., 2013. Qualitative Research in Sport and Physical Activity. London: SAGE.

Joseph, D. L. and Newman, D. A., 2010. Emotional intelligence: an integrative meta-analysis and cascading model. The Journal Of Applied Psychology, 95 (1), 54-78.

Kalwani, S. and Mahesh, J., 2020. Trends in organizational behavior: A systematic review and research directions. Journal of Business \& Management, 26 (1), 40-78.

Kang, H. J., Gatling, A. and Kim, J., 2015. The impact of supervisory support on organizational commitment, career satisfaction, and turnover intention for hospitality frontline employees. Journal of Human Resources in Hospitality \& Tourism, 14 (1), 68-89.

Keefer, K. V., Parker, J. D. and Saklofske, D. H., 2018. Three decades of emotional intelligence research: Perennial issues, emerging trends, and lessons learned in education: Introduction to emotional intelligence in education. Emotional intelligence in education. Springer, 1-19.

Kemppainen, J. K., 2000. The critical incident technique and nursing care quality research. Journal of Advanced Nursing, 32 (5), 1264-1271.

Kim, H. and Qu, H., 2019. Employees' burnout and emotional intelligence as mediator and moderator in the negative spiral of incivility. International Journal of Contemporary Hospitality Management, 31 (3), 1412-1431.

Kim, H. J. and Agrusa, J., 2011. Hospitality service employees' coping styles: The role of emotional intelligence, two basic personality traits, and socio-demographic factors. International Journal of Hospitality Management, 30 (3), 588-598.

Kim, J.-H. and Jang, S., 2016. Factors affecting memorability of service failures: A longitudinal analysis. International Journal of Contemporary Hospitality Management, 28 (8), 1676-1701. 
Kim, T., Yoo, J. J.-E., Lee, G. and Kim, J., 2012. Emotional intelligence and emotional labor acting strategies among frontline hotel employees. International Journal of Contemporary Hospitality Management, 24 (7), 1029-1046.

Knežević, M. N., Petrović, M. D., Kovačić, S., Mijatov, M., Vuković, D. B. and Kennell, J., 2021. Acting the part: Emotional intelligence and job satisfaction as predictors of emotional labor in travel agencies. Tourism \& Hospitality Research, 21 (2), 183-201.

Koc, E., 2019. Service failures and recovery in hospitality and tourism: a review of literature and recommendations for future research. Journal of Hospitality Marketing and Management, 28 (5), 513-537.

Kong, H., Yuan, Y., Baruch, Y., Bu, N., Jiang, X. and Wang, K., 2021. Influences of artificial intelligence (AI) awareness on career competency and job burnout. International Journal of Contemporary Hospitality Management, 33 (2), 717-734.

Lam, R., Cheung, C. and Lugosi, P., 2020. The impacts of cultural and Emotional Intelligence on hotel guest satisfaction: Asian and Non-Asian perceptions of staff capabilities. Journal of China Tourism Research, 17 (3), 455-477.

Lawrence, S., A., Troth, A., C., Jordan, P., J. and Collins, A., L., 2011. A review of emotion regulation and development of a framework for emotion regulation in the workplace. In: Perrewe, P. L. and Ganster, D. C., eds. The Role of Individual Differences in Occupational Stress and Well Being. Emerald Group Publishing Limited, 197-263.

Lee, J. and Ok, C., 2015. Examination of factors affecting hotel employees' service orientation: An emotional labor perspective. Journal of Hospitality \& Tourism Research, 39 (4), 437-468.

Lee, J. H. and Ok, C. H., 2012. Reducing burnout and enhancing job satisfaction: Critical role of hotel employees' emotional intelligence and emotional labor. International Journal of Hospitality Management, 31 (4), 1101-1112.

Lee, L. and Madera, J. M., 2019a. A systematic literature review of emotional labor research from the hospitality and tourism literature. International Journal of Contemporary Hospitality Management, 31 (7), 2808-2826.

Lee, L. and Madera, J. M., 2019b. Faking it or feeling it: The emotional displays of surface and deep acting on stress and engagement. International Journal of Contemporary Hospitality Management, 31 (4), 1744-1762.

Lei, N. and Pellitteri, J., 2017. Help-seeking and coping behaviors among Asian Americans: The roles of Asian values, emotional intelligence, and optimism. Asian American Journal of Psychology, 8 (3), 224-234.

Lincoln, Y. S., 2009. Rethinking emotional intelligence: An alternative proposal. Advances in Developing Human Resources, 11 (6), 784-791.

Lindebaum, D., 2015. A qualitative study of emotional intelligence and its underlying processes and outcomes in management studies. In: Härtel, C. E. J., Zerbe, W. J. and Ashkanasy, N. M., eds. New ways of studying emotions in organizations. Bingley, United Kingdom: Emerald Group Publishing, 109-137.

Lopes, P. N., 2016. Emotional Intelligence in organizations: Bridging research and practice. Emotion Review, 8 (4), 316-321.

Lyu, S. H., 2012. Development and mission of Theravada and Mahayana Buddhism in an era of globalization. Religion East \& West, 11, 45-51.

Manzur, L. and Jogaratnam, G., 2006. Impression management and the hospitality service encounter: cross-cultural differences. Journal of Travel \& Tourism Marketing, 20 (3/4), 21-32.

Mariani, M. M., Borghi, M. and Kazakov, S., 2019. The role of language in the online evaluation of hospitality service encounters: An empirical study. International Journal of Hospitality Management, 78, 50-58. 
Markus, H. R. and Kitayama, S., 1991. Culture and the self: Implications for cognition, emotion, and motivation. Psychological Review, 98 (2), 224-253.

Matthews, G., Emo, A. K., Roberts, R. D. and Zeidner, M., 2006. What is this thing called Emotional Intelligence? In: Murphy, K. R., ed. A Critique of Emotional Intelligence: What are the problems and How can they be fixed? New Jersey: Lawrence Erlbaum Associates, 3-36.

Mayer, J. D., Caruso, D. R. and Salovey, P., 2016. The ability model of Emotional Intelligence: principles and updates. Emotion Review, 8 (4), 290-300.

Mayer, J. D. and Salovey, P., 1997. What is emotional intelligence? In: Salovey, P. and Sluyter, D. J., eds. Emotional development and Emotional Intelligence: Educational implications. New York: BasicBooks, 3-31.

McCleskey, J., 2014. Emotional intelligence and leadership : A review of the progress, controversy, and criticism. International Journal of Organizational Analysis, 22 (1), 76-93.

Miao, C., Humphrey, R. H. and Qian, S., 2021. Emotional intelligence and job performance in the hospitality industry: a meta-analytic review. International Journal of Contemporary Hospitality Management, 33 (8), 2632-2652.

Min, J., Cobanoglu, C. and Hui-Wen Tang, V., 2020. The relationship between Emotional Intelligence (EI) and Quality of Life (QOL) in Taiwanese undergraduates. International Journal of Organizational Innovation, 13 (2), 55-69.

Moon, T., 2010. Emotional intelligence correlates of the four-factor model of cultural intelligence. Journal of Managerial Psychology, 25 (8), 876-898.

Moreo, A., Woods, R., Sammons, G. and Bergman, C., 2019. Connection or competence: Emotional labor and service quality's impact on satisfaction and loyalty. International Journal of Contemporary Hospitality Management, 31 (1), 330-348.

Newman, M. and Smith, K. H., 2014. Emotional Intelligence and emotional labour: A comparison study using the Emotional Capital Report (ECR). Education \& Society, 32 (1), 41-62.

Nguyen, M. and Truong, M., 2016. The effect of culture on enterprise's perception of Corporate Social Responsibility: The case of Vietnam. Procedia CIRP, 40, 680-686.

Petrides, K. V., 2010. Trait Emotional Intelligence theory. Industrial and Organizational Psychology, 3 (2), 136-139.

Pham, H. D., 2015. Problems and conflicts in managing international joint ventures in Vietnam. Philippine Management Review, 20, 47-64.

Prati, L. M., Douglas, C., Ferris, G., R., Ammeter, A., P. and Buckley, M. R., 2003. The role of Emotional Intelligence in team leadership: Reply to the critique by Antonakis. The International Journal of Organizational Analysis, 11 (4), 363-369.

Prentice, C., Dominique Lopes, S. and Wang, X., 2020. Emotional intelligence or artificial intelligence - an employee perspective. Journal of Hospitality Marketing and Management, 29 (4), 377-403.

Ro, H. and Wong, J., 2012. Customer opportunistic complaints management: A critical incident approach. International Journal of Hospitality Management, 31, 419-427.

Romero, J. and Lado, N., 2021. Service robots and COVID-19: exploring perceptions of prevention efficacy at hotels in generation Z. International Journal of Contemporary Hospitality Management. https://doi.org/10.1108/IJCHM-1110-2020-1214.

Salovey, P. and Mayer, J. D., 1990. Emotional Intelligence. Imagination, cognition and personality, 9 (3), 185-211.

Saunders, M., Lewis, P. and Thornhill, A., 2012. Research methods for business students. 6th edition. Harlow: Pearson. 
Schimmack, U., 1996. Cultural influences on the recognition of emotion by facial expressions: Individualistic or Caucasian cultures? Journal of Cross-Cultural Psychology, 27 (1), 37-50.

Scott-Halsell, S., Blum, S. C. and Huffman, L., 2011. From school desks to front desks: A comparison of emotional intelligence levels of hospitality undergraduate students to hospitality industry professionals. Journal of Hospitality, Leisure, Sport \& Tourism Education, 10 (2), 3-13.

Sternberg, R. J., 2001. Measuring the Intelligence of an idea: How intelligent is the idea of Emotion Intelligence? In: Ciarrochi, J. V., Forgas, J. P. and Mayer, J. D., eds. Emotional Intelligence in everyday life: A scientific inquiry. Philadelphia: Taylor \& Francis, 187-194.

Stoyanova-Bozhkova, S., Paskova, T. and Buhalis, D., 2020. Emotional intelligence: a competitive advantage for tourism and hospitality managers. Tourism Recreation Research, 1-13.

Tabari, S., Wilson, J. A. J. and Ingram, H., 2016. Conceptualising the impact of culture and language upon hospitality service management. Worldwide Hospitality and Tourism Themes, 8 (1), 12-28.

Viergever, R. F., 2019. The critical incident technique: Method or methodology? Qualitative Health Research, 29 (7), 1065-1079.

Wang, X., Guchait, P., Khoa, D. T. and Pasamehmetoglu, A., 2021. Experience of shame in service failure context among restaurant frontline employees: does industry tenure matter? International Journal of Contemporary Hospitality Management, 33 (8), 2817-2838.

Wang, X. L., 2012. Relationship or revenue: Potential management conflicts between customer relationship management and hotel revenue management. International Journal of Hospitality Management, 31 (3), 864-874.

Wang, Z. and Xie, Y., 2020. Authentic leadership and employees' emotional labour in the hospitality industry. International Journal of Contemporary Hospitality Management, 32 (2), 797-814.

Werner, J., 2004. State Subject-making and Womanhoods in the Red River Delta of Vietnam, 115.

Wranik, T., Barrett, L. F. and Salovey, P., 2007. Intelligent Emotion Regulation: Is Knowledge Power? In: Gross, J. J., ed. Handbook of emotion regulation. New York, NY, US: Guilford Press, 393-407.

Wu, L. Z., Ye, Y., Lyu, Y., Cheng, X. M. and Kwan, H. K., 2020. Fuel the service fire: The effect of leader humor on frontline hospitality employees' service performance and proactive customer service performance. International Journal of Contemporary Hospitality Management, 32 (5), 1755-1773.

Wu, X., Shie, A.-J. and Gordon, D., 2017. Impact of customer orientation on turnover intention: Mediating role of emotional labour. International Journal of Organizational Analysis, 25 (5), 909-927.

Yick, M. Y. Y., Köseoglu, M. A. and King, B., 2020. Gazing at hotel guests: Deconstructing elements of the host-gaze. International Journal of Hospitality Management, 87, 102508.

Yu, Y., Kim, H. and Qu, H., 2020. A deep acting perspective generation Y hotel employees' workplace deviance. International Journal of Contemporary Hospitality Management, 32 (2), 835-852. 